\title{
FRAGRANCE COMPOSITION OF DENDROPHYLAX LINDENII (ORCHIDACEAE) USING A NOVEL TECHNIQUE APPLIED IN SITU
}

\author{
JAMES J. SADLER ${ }^{1, *}$, JACLYN M. SMITH ${ }^{1}$, LAWRENCE W. ZETTLER ${ }^{1}$, \\ HANS T. ALBORN ${ }^{2}$, and LARRY W. RICHARDSON ${ }^{3}$
}

${ }^{1}$ Orchid Recovery Program, Department of Biology, Illinois College, 1101 West College Avenue, Jacksonville, IL 62650, USA

2 U.S. Department of Agriculture, 1600-1700 SW 23rd Drive, Gainesville, FL 32608, USA

${ }^{3}$ Florida Panther National Wildlife Refuge, U.S. Fish and Wildlife Service, 3860 Tollgate Boulevard, Suite 300, Naples, FL 34114, USA

*Corresponding author: jjsadler@ufl.edu; Tel.: (618) 967-9465; Fax: (352) 392-1413

Present address: Department of Environmental Horticulture, P.O. Box 110675, Building 68 IFAS Research Drive, Gainesville, FL 32611, USA

\begin{abstract}
The ghost orchid, Dendrophylax lindenii (Lindley) Bentham ex Rolfe (Orchidaceae), is one of North America's rarest and well-known orchids. Native to Cuba and SW Florida where it frequents shaded swamps as an epiphyte, the species has experienced steady decline. Little information exists on D. lindenii's biology in situ, raising conservation concerns. During the summer of 2009 at an undisclosed population in Collier County, FL, a substantial number (ca. 13) of plants initiated anthesis offering a unique opportunity to study this species in situ. We report a new technique aimed at capturing floral headspace of $D$. lindenii in situ, and identified volatile compounds using gas chromatography mass spectrometry (GC/MS). All components of the floral scent were identified as terpenoids with the exception of methyl salicylate. The most abundant compound was the sesquiterpene $(E, E)$ - $\alpha$-farnesene $(71 \%)$ followed by $(E)-\beta$-ocimene $(9 \%)$ and methyl salicylate (8\%). Other compounds were: linalool (5\%), sabinene (4\%), (E)-a-bergamotene (2\%), $a$-pinene (1\%), and 3-carene (1\%). Interestingly, $(E, E)$-a-farnesene has previously been associated with pestiferous insects (e.g., Hemiptera). The other compounds are common floral scent constituents in other angiosperms suggesting that our in situ technique was effective. Volatile capture was, therefore, possible without imposing physical harm (e.g., inflorescence detachment) to this rare orchid.
\end{abstract}

Keywords: ghost orchid, South Florida, $(E, E)$ - $a$-farnesene, volatiles, scent, conservation

\section{Introduction}

Few orchids native to North America have received as much widespread interest as the ghost orchid, Dendrophylax lindenii (Lindley) Bentham ex Rolfe (Orchidaceae) - the subject of best-selling books and a hit movie. The species is restricted to Cuba and the Big Cypress eco-region of S Florida (e.g., the Fakahatchee Strand; Brown 2005) where it frequents shaded swamps as an epiphyte. In SW Florida, the species has experienced steady decline due to habitat loss and poaching. The public's fascination with this species is attributed, in part, to its alluring floral display (Fig. 1). At maturity, D. lindenii is leafless and only a small percentage of plants in a population flower in a given year. Although advances are being made to propagate this species artificially (e.g., Davis 2009), the process has been slow and often unreliable. This fact, coupled with the orchid's rarity and inaccessibility, has resulted in its widespread removal (poaching) from protected and private areas by unscrupulous collectors. Currently, the species is listed as endangered in Florida (Brown 2005) where its natural range is mostly restricted to two counties undergoing rapid urban development.

To facilitate the sustainable conservation of $D$. lindenii and other orchids worldwide, habitat preservation must be augmented by understanding the species' ecological requirements in situ, including pollination and breeding systems (= integrated conservation; Stewart 2007;
Swarts 2007). Only ca. $36 \%$ of orchid species native to North America have been studied with respect to their pollination mechanisms (Catling and Catling 1991), and even less is known about the chemical attractants utilized

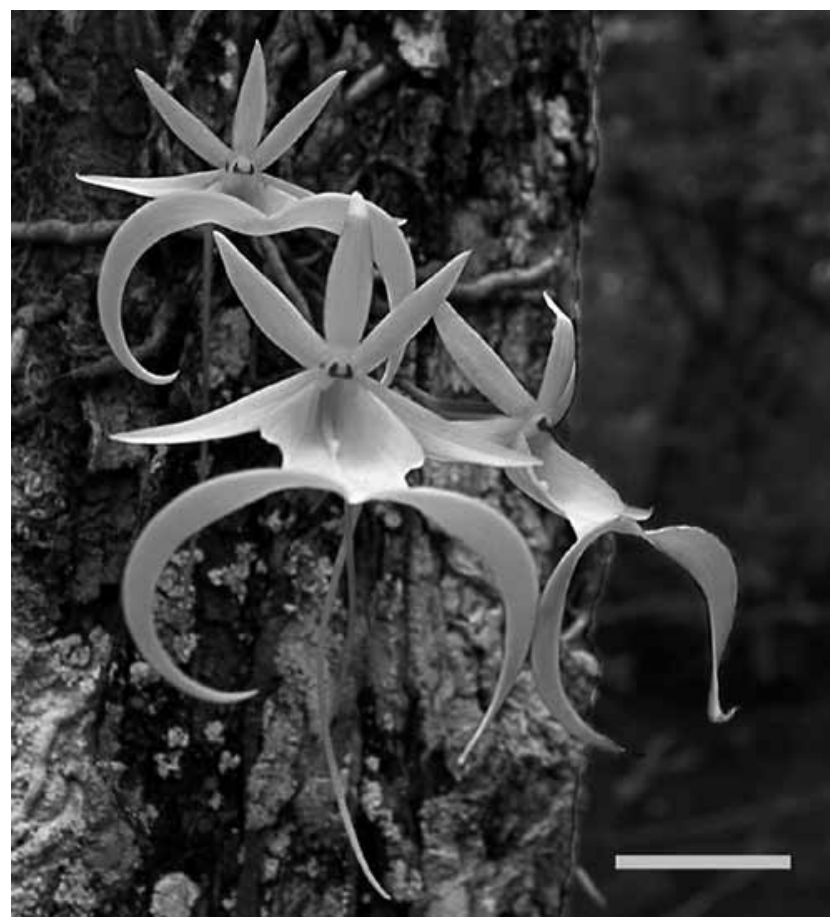

Fig. 1 The ghost orchid (Dendrophylax lindenii) in flower in southwest Florida (2009). The long nectar spur can be seen beneath the lower lip (labellum) of the flowers. Scale bar $=6 \mathrm{~cm}$. 
by these species to attract pollinators (floral scent). Currently, no published reports exist that describe natural pollination or floral fragrance chemistry of $D$. lindenii. The species' floral characteristics, namely the long nectar spur, white color, and sweet smelling evening fragrance (pers. observations), suggest pollination by sphinx moths (Faegri and van der Pijl 1979; Dressler 1981; Grant 1983).

During the summer of 2009 at a restricted, undisclosed D. lindenii population in Collier Co., FL, a substantial number (ca. 13) of individual plants initiated anthesis. Several of these plants flowered $<2 \mathrm{~m}$ from the forest floor, offering a unique research opportunity to study this species in situ. We hypothesized that the ghost orchid would produce aromatic compounds that attract nightflying insects and would have a similar composition to other moth-pollinated orchids. If a similar composition, compared to other angiosperms and orchids, is achieved then the novel technique of headspace collection can be utilized for other epiphytic species. In this paper we report the primary floral fragrance compounds emitted by the ghost orchid using an adsorbent that serves to trap volatile compounds in situ, followed by laboratory analysis by means of GC/MS. The technique described herein (modified from Kaiser 1993) allows for volatile compound capture without imposing physical harm (e.g., inflorescence detachment) to this rare orchid.

\section{Materials and methods}

\section{Study site}

Samples were obtained from a restricted Dendrophylax lindenii (Lindley) Bentham ex Rolfe population on private property in Collier Co., FL. (The exact location of this site is withheld here to reduce the likelihood of subsequent poaching.) Compared to other ghost orchid populations throughout S Florida, this location harbored a sizable number of plants (ca. 50 individuals), 13 of which produced flowers in June 2009. In previous years (e.g., 2008), plants from this population produced mature seed capsules, suggesting that the flowers are naturally pollinated at this site. The majority of the orchids were affixed to the bark of pond-apple (A. glabra L.) on low hanging branches ca. $2 \mathrm{~m}$ above the sediment floor.

\section{Volatile sampling}

During a 2 day period (22-23 June 2009), three flowers from three individual plants were sampled in the early morning hours (100-600 hrs) when fragrance was most readily detected by the authors. Volatiles were collected using an apparatus modified from Kaiser (1993) that was modified for arboreal fragrance extraction (Figs. 2 and 3). Volatile adsorption was carried out using the procedure described by Cancino and Damon (2007). The adsorbent was washed with diethyl ether before use. After 2-3 hrs of

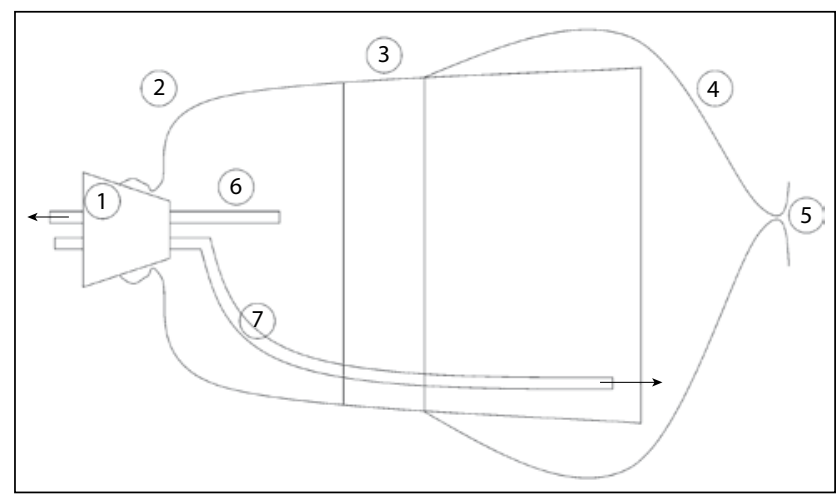

Fig. 2 Diagram of the apparatus (modified from Kaiser, 1993) used to absorb floral volatiles in situ. (1) rubber stopper; (2) glass bell flask; (3) Parafilm "M" (Pechiney Plastic Packaging, Menasha, WI) securing oven bag on outside of bell flask; (4) plastic-like oven bag (Reynolds Kitchens, Richmond, VA); (5) opening to allow flower in apparatus and to close around stem; (6) headspace pumped out of flask via mechanical pump through adsorbent; (7) activated charcoal-filtered air from environment.

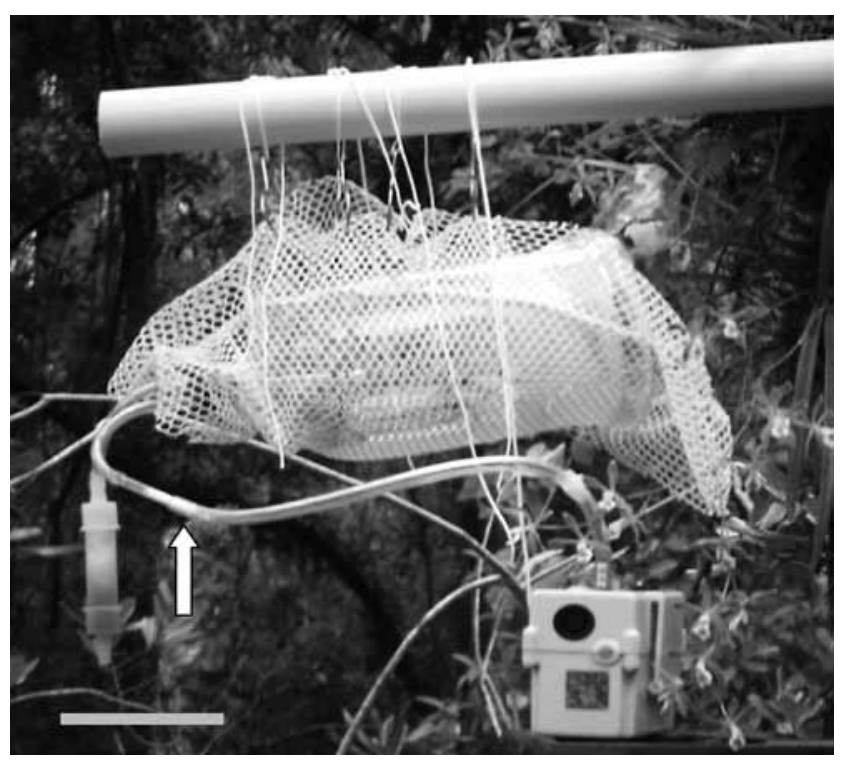

Fig. 3 The apparatus (modified from Kaiser 1993) enclosing inflorescences in situ while suspended from the canopy of the host tree and a stand constructed from PVC pipe. The vacuum pump and charcoal adsorbent can be seen at the lower right and lower left, respectively. The Porapak Q adsorbent is denoted by the arrow. Scale bar $=15 \mathrm{~cm}$.

adsorption, the volatiles were eluted with ca. $1200 \mu \mathrm{L}$ of diethyl ether into glass vials and stored at $-70{ }^{\circ} \mathrm{C}$ prior to laboratory analysis (2 days). The samples were briefly (6 hrs) removed from storage when they were transported by car to Gainesville, FL for analysis. During transport, vials were placed into a portable cooler containing dry ice.

\section{Analysis of volatiles}

The samples were analyzed on an Agilent 6890/5973 coupled GC/MS. One $\mu \mathrm{l}$ of the samples were introduced using splitless injection at $220^{\circ} \mathrm{C}$. A $30 \mathrm{~m} \mathrm{DB} 1$ methyl silicone GC-column with $0.25 \mathrm{~mm}$ ID and a film thickness of $0.25 \mu \mathrm{m}$ was used with helium carrier gas at constant 
flow with an average velocity of $30 \mathrm{~cm} / \mathrm{sec}$. The GC oven had an initial temperature of $35^{\circ} \mathrm{C}$ for $0.5 \mathrm{~min}$ and then programmed $10{ }^{\circ} \mathrm{C}$ per minute to a final temperature of $230^{\circ} \mathrm{C}$ and maintained at this temperature for $5 \mathrm{~min}$. The injector and MS transfer line temperature was $240{ }^{\circ} \mathrm{C}$. The ion source temperature was $220^{\circ} \mathrm{C}$ with EI ionization at $70 \mathrm{eV}$ and the quadruple scan range set to $\mathrm{m} / \mathrm{z} 30$ to 400 with a 2 scan averaging giving a scan rate of 3.85 scan-1. The GC/MS data were processed using Agilent Chemstation version 3.02. Compounds were identified by comparison with commercially available NIST05 and Adams EO libraries and a floral scent library created at the department of Chemical Ecology, Göteborg University, Sweden and when possible by utilizing mass spectra of commercial standards.

\section{Results and Discussion}

GC/MS analysis revealed 8 compounds associated with the floral fragrance of $D$. lindenii (Fig. 4). Samples obtained from three different plants during a two day period yielded similar results. These compounds consisted

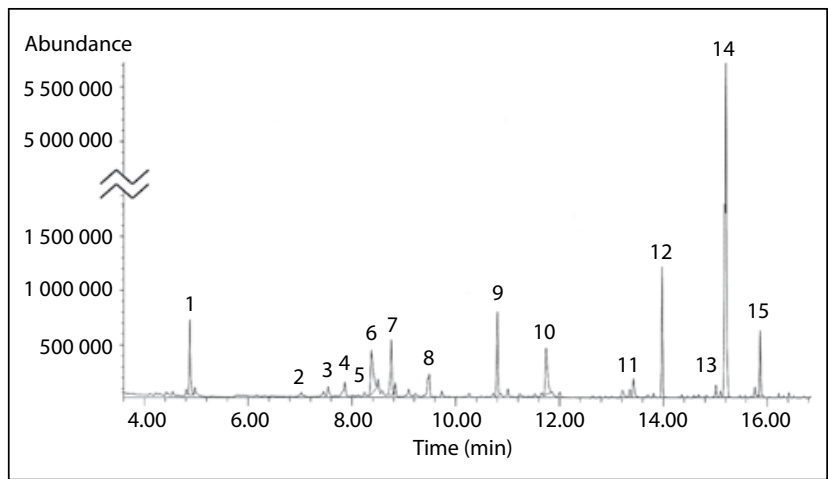

Fig. 4 GC spectra analysis of 15 peaks: (1) solvent background; (2) a-pinene; (3) 6-methyl-5-hepten-2-one; (4) myrcene; (5) 3-carene; (6) sabinene; (7) (E)- $\beta$-ocimene; (8) linalool; (9) methyl salicylate; (10) geraniol; (11) phenylbenzene; (12) tetradecane; (13) (E)-a-bergamotene; (14) (E,E)-a-farnesene; (15) Diethyl phthalate. Compound names that are italicized indicate confidence that these were from the ghost orchid.

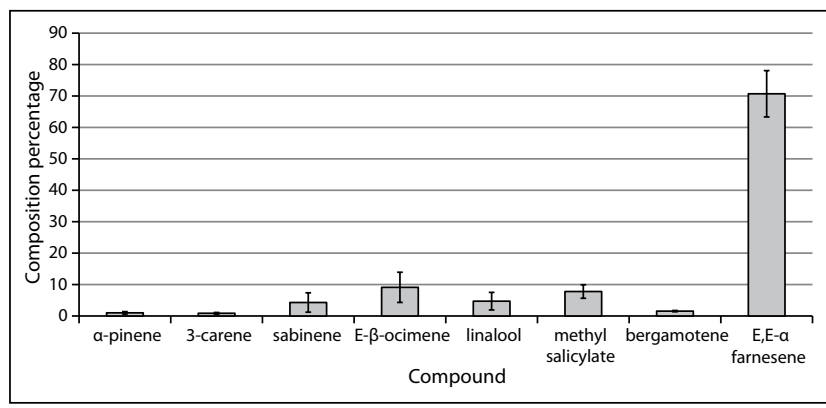

Fig. 5 Composition as a percentage for the eight volatile compounds that comprise the floral scent of Dendrophylax lindenii. Error bars reflect \pm standard deviation.

mostly of monoterpenes, along with sesquiterpenes and benzenoids. The most prevalent compound was the sesquiterpene (E,E)- $\alpha$-farnesene (Figs. 4 and 5 , Table 1). The other 7 compounds detected were $\alpha$-pinene, 3 -carene, sabinene, $(E)$ - $\beta$-ocimene, linalool, methyl salicylate, and $(E)$ - $\alpha$-bergamotene. The other compounds presented in the chromatogram (Fig. 4) occasionally occur as background in GC/MS analyses of volatile collections.

This is the first report describing the chemical composition of $D$. lindenii's floral scent. Although the sample size was low, the results were reproducible. With the exception of $(E, E)$ - $\alpha$-farnesene, all of the compounds were common floral scent constituents, verifying that our in situ technique was effective. Of the 90 plant families investigated for floral fragrance compounds worldwide, orchids have received the most attention (417 spp./subspp.), followed by aroids (Araceae, 55 spp./subspp.) and palms (Arecaceae, 40 spp./subspp.) (Knudsen et al. 2006). While this total might appear sizable, the vast majority of the Orchidaceae $(>97 \%)$ remains unstudied considering that the family contains an estimated $17,000-35,000$ species (Dressler 1993). Other plant families have been studied with respect to floral scent (e.g., Magnoliaceae, Rosaceae, Cactaceae, Rutaceae, Solanaceae, and Nyctaginaceae), but this aspect of angiosperm biology remains poorly understood (Knudsen et al. 2006). Nevertheless, a pattern of floral scent compounds is starting to emerge. For example,

Table 1 The percent composition of the primary volatile compounds collected from the ghost orchid's scent. Notice the percents add to 100 to ease comparison between the eight compounds of the four trials. Trial 1 is displayed in Fig. 4. Four replicates were done during the same time period between different orchid flowers.

\begin{tabular}{|c|c|c|c|c|c|c|c|}
\hline \multirow{2}{*}{ Rt (min) } & \multirow{2}{*}{ Compound } & \multicolumn{4}{|c|}{ Floral Scent Percent Composition } & \multirow{2}{*}{ Mean } & \multirow{2}{*}{$\begin{array}{l}\text { Standard } \\
\text { Deviation }\end{array}$} \\
\hline & & Trial 1 & Trial 2 & Trial 3 & Trial 4 & & \\
\hline 7.054 & a-pinene & 0.672 & 1.410 & 0.668 & 1.245 & 0.999 & 0.386 \\
\hline 8.266 & 3-carene & 0.704 & 0.822 & 0.694 & 1.228 & 0.862 & 0.251 \\
\hline 8.517 & sabinene & 1.718 & 2.457 & 4.384 & 8.601 & 4.290 & 3.086 \\
\hline 8.773 & (E)- $\beta$-ocimene & 7.922 & 7.052 & 5.337 & 16.139 & 9.112 & 4.806 \\
\hline 9.515 & linalool & 2.607 & 7.559 & 2.022 & 6.647 & 4.709 & 2.800 \\
\hline 10.822 & methyl salicylate & 9.281 & 7.353 & 9.592 & 4.906 & 7.783 & 2.159 \\
\hline 15.037 & (E)-a-bergamotene & 1.543 & 1.653 & 1.726 & 1.250 & 1.543 & 0.209 \\
\hline 15.249 & $(\mathrm{E}, \mathrm{E})$-a-farnesene & 75.553 & 71.693 & 75.577 & 59.984 & 70.702 & 7.375 \\
\hline
\end{tabular}


more than two-thirds of the families investigated to date (> 66\%) share a common profile consisting of five compounds: limonene $(71 \%),(E)-\beta$-ocimene $(71 \%)$, myrcene (70\%), linalool (70\%), and $\alpha$-pinene (67\%) (Knudsen et al. 2006). With the exception of limonene and myrcene, these five basic compounds are also present in the floral scent of $D$. lindenii. The other compounds (3-carene, sabinene, methyl salicylate, $(E)$ - $\alpha$-bergamotene, $(E, E)$ $\alpha$-farnesene) appear to be less prevalent among the angiosperm families studied so far; however, all but one (3-carene) have been reported from moth-pollinated Orchidaceae (Knudson et al. 2006).

From an ecological perspective, the link (specificity) between an orchid's fragrance and its pollinator is determined by the proportion (blend) of the compounds emitted, not just by the kinds of chemicals that are produced (J.A. Yoder, pers. comm.). In this case, the blend released by $D$. lindenii consisted of the sesquiterpene $(E, E)$ - $\alpha$-farnesene $(71 \%)$ followed by $(E)$ - $\beta$-ocimene (9\%) and methyl salicylate (8\%). Other compounds were linalool (5\%), sabinene (4\%), (E)- $\alpha$-bergamotene $(2 \%)$, $\alpha$-pinene (1\%), and 3-carene (1\%) (Fig. 3). At close range (ca. $5 \mathrm{~cm}$ ), the floral scent of $D$. lindenii was readily detectable to the authors and seemed to intensify at sunset (pers. observations). The scent can best be described as sweet-smelling and somewhat fruity. Of particular interest is $(E, E)$ - $\alpha$-farnesene - the most abundant constituent. This compound is odorless to humans and has been linked with insects and insect-damaged plants as well as intact plants (Himanen et al. 2005). Similarly, aphids (Hemiptera: Aphidae) release trans- $\beta$-farnesene as an alarm pheromone from the tips of their cornicles when attacked or disturbed (Yang and Zettler 1975). Indeed, pestiferous

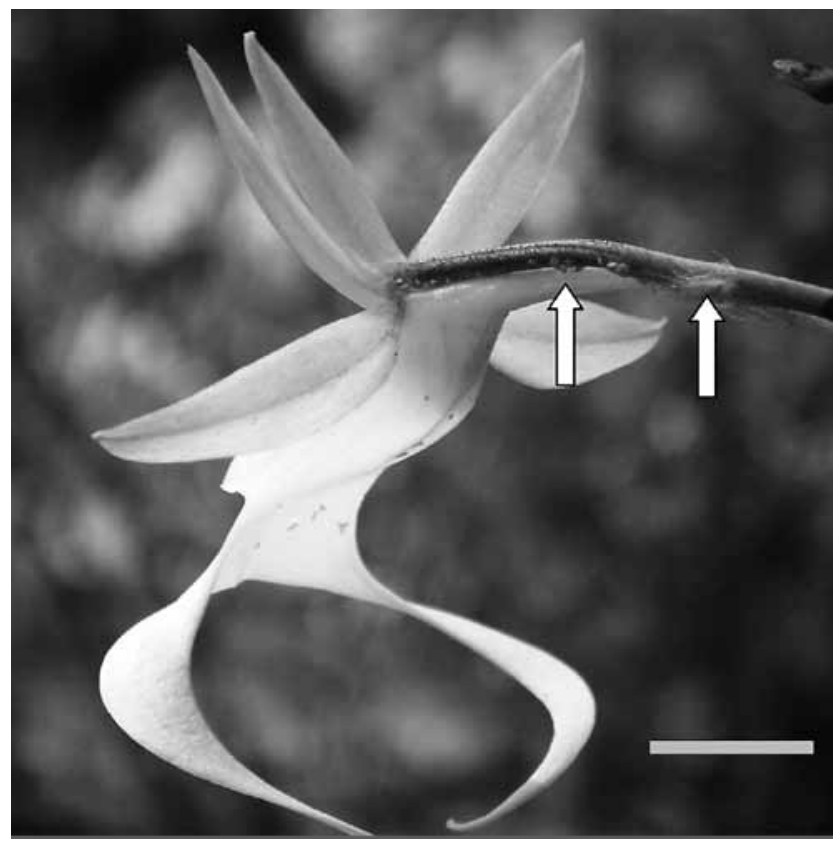

Fig. 6 A Dendrophylax lindenii flower photographed during one of the two sampling days (22-23 June 2009). Pestiferous insects (Hemiptera) can be seen on the developing ovary and are denoted by the arrows. Scale bar $=3 \mathrm{~cm}$. scale insects (Hemiptera) were observed on ovaries of inflorescences at the time of sampling (Fig. 6). During a follow-up visit (24 July 2009), some of these insects were collected and later identified as members of the Coccidae and Pseudococcidae (J. A. Zettler, L. W. Zettler, L. W. Richardson, unpubl. data). Whether or not the presence of these insects triggered the release of $(E, E)$ - $\alpha$-farnesene captured in the sample is not known, but cannot be ruled out. Additional studies should explore whether the insects, the plant, or both are releasing this compound.

The highlight of this study was the technique (modified from Kaiser 1993) used to collect headspace volatiles from $D$. lindenii in situ without imposing physical harm to the donor plants (Figs. 2 and 3). This was achieved by suspending the adsorption apparatus from rope affixed to branches within the immediate area (canopy). The use of a lightweight, battery-powered vacuum permitted suitable airflow and subsequent capture of volatiles within glass vials containing Porapak Q adsorbent (Chromatography Research Supplies, Louisville, KY). Our technique fundamentally differs from the methods used in previous studies (e.g., Dutra et al. 2009) because in the latter, inflorescences are detached from donor plants and analyzed. For critically rare species in peril, the removal of inflorescences for this purpose may not be desirable or legally possible. Our sampling technique makes it possible for flowers to be receptive to pollination after sampling, increasing the likelihood of seed set. Clearly, this method would be practical for conservation programs involving other rare epiphytic orchids, as well as non-orchids (e.g., Bromeliaceae, Cactaceae, Piperaceae).

Other useful applications await researchers that adopt this technique, both in situ and in vivo. For example, intact plants may be sampled during an extended period of time (e.g., weeks or months). This might serve a useful purpose for those interested in documenting changes in the proportion (blend) of the compounds emitted over time. Yang et al. (2009) linked floral scent in a non-orchid (Delphinium elatum L., Ranunculaceae) to its substrate, and it is conceivable that this same phenomenon might also be observed in the Orchidaceae. Orchids would be of special interest given that these plants obtain all or part of their carbon from mycorrhizal fungi (via mycotrophy) present in the substrate (Rasmussen 1995). This technique might make it possible to monitor long-term changes in floral scent through the manipulation of substrate, fungi or both. In the short-term, we urge other researchers to document floral fragrance composition in other rare native orchids as part of a holistic (integrated) approach to conservation.

\section{Conclusions}

Eight primary volatile compounds comprise the floral scent of the ghost orchid, Dendrophylax lindenii. The technique described herein permitted the collection of 
floral scent compounds in situ with minimal or no disturbance to this rare orchid. This technique may have practical merit for similar studies aimed at other epiphytic species in peril.

\section{Acknowledgements}

The authors warmly thank Andy Stice (Illinois College) for acquiring all necessary materials for the apparatus and Dr. Gary Grams (Illinois College) for technical assistance. Thanks are also extended to Dr. Michael Kane (University of Florida) and Dr. Jay A. Yoder (Wittenberg University) for critique of the manuscript. We also acknowledge Dr. Jennifer A. Zettler (Armstrong Atlantic State University) for collection and identification of scale insects and Dr. Barbara Carlsward (Eastern Illinois University) for helpful information. This project was funded by the U.S. Fish and Wildlife Service and Illinois College's StudentFaculty Research Committee for which we are grateful.

\section{REFERENCES}

Brown PM (2005) Wild Orchids of Florida. University Press of Florida, Gainesville, FL.

Cancino ADM, Damon A (2007) Fragrance analysis of euglossine bee pollinated orchids from Soconusco, south-east Mexico. Plant Species Biology 22: 129-134.

Catling PM, Catling VR (1991) A synopsis of breeding systems and pollination in North American orchids. Lindleyana 6: 187-210.

Davis K (2009) How to grow the Ghost Orchid: From Seedling to Flowering. Orchids 78(7): 414-415.

Dressler RL (1981) The Orchids-Natural History and Classification. Harvard University Press, Cambridge, UK.
Dressler RL (1993) Phylogeny and Classification of the Orchid Family. Dioscorides Press, Portland, OR.

Dutra D, Kane ME, Adams CR, Richardson LW (2009) Reproductive biology of Cyrtopodium puncatum in situ: implications for conservation of an endangered Florida orchid. Plant Species Biology 24: 92-103.

Faegri K, van der Pijl L (1979) The Principles of Pollination Ecology (3rd ed.). Pergamon Press, Oxford, UK.

Grant V (1983) The systematic and geographical distribution of hawkmoth flowers in the temperate North American flora. Botanical Gazette 144: 439-449.

Himanen S, Vuorinen T, Tuovinen T, Holopainen JK (2005) Effects of cyclame mite (Phytonemus pallidus) and leaf beetle (Galerucella tenella) damage on volatile emission from strawberry (Fragaria $\mathrm{x}$ ananassa Duch.) plants and orientation of predatory mites (Neoseiulus cucumeris, N. californicus, and Euseius finlandicus). J. Agric. Food Chem. 53: 8624-8630.

Kaiser R (1993) The Scent of Orchids: Olfactory and Chemical Investigations. Elsevier Science, Amsterdam, Netherlands.

Knudsen JT, Eriksson R, Gershenzon, J (2006) Diversity and distribution of floral scent. The Botanical Review 72(1): 1-120.

Rasmussen HN (1995) Terrestrial Orchids: From Seed to Mycotrophic Plant. Cambridge University Press, Cambridge, UK.

Stewart SL (2007) Integrated conservation of Florida Orchidaceae in the genera Habenaria and Spiranthes: Model Orchid Conservation Systems for the Americas. PhD Thesis, University of Florida, Gainesville.

Swarts N (2007) Integrated conservation of the rare and endangered terrestrial orchid Caladenia huegelii H.G. Reichb. PhD Thesis, University of Western Australia, Perth.

Yang SL, Zettler FW (1975) Effects of alarm pheromones on aphid probing behavior and virus transmission efficiency. Plant Disease Reporter 59: 902-905.

Yang Z, Endo S, Tanida A, Kai K, Watanabe N (2009) Synergy effect of sodium acetate and glycosidically bound volatiles on the release of volatile compounds from the unscented cut flower (Delphinium elatum L. "Blue Bird"). J. Agric. Food Chem. 57: 6396-6401. 